\title{
A Summary on Research of Household Energy Consumption: A Bibliometric Analysis
}

\author{
Xiaowei Ma ${ }^{1,2,3,4, *(\mathbb{D}}$, Mei Wang ${ }^{1,2}$ and Chuandong $\mathrm{Li}^{1,2}{ }^{1 / D}$ \\ 1 Center for Energy and Environmental Policy Research, Beijing Institute of Technology, Beijing 100081, China; \\ 7220171131@bit.edu.cn (M.W.); 3120181476@bit.edu.cn (C.L.) \\ 2 School of Management and Economics, Beijing Institute of Technology, Beijing 100081, China \\ 3 Beijing Key Laboratory of Energy Economics and Environmental Management, Beijing 100081, China \\ 4 Sustainable Development Research Institute for Economy and Society of Beijing, Beijing 100081, China \\ * Correspondence: xiaoweibit@163.com or maxiaowei@bit.edu.cn; Tel.: +86-010-6891-8454
}

Received: 16 December 2019; Accepted: 28 December 2019; Published: 31 December 2019

check for updates

\begin{abstract}
With the emergence of the contradictions between energy supply and demand, considerable attention has been paid to the residential household energy consumption with increasing research in this field. Based on databases of Science Citation Index Expanded and Social Sciences Citation Index, this paper applies the bibliometric method to analyze the development and evolution of this research field using the literature published in the field of residential energy consumption during the period 1970-2018. The following findings were found: (1) The research on energy consumption of households is mainly divided into three stages: cognition (1970-1989), exploration (1990-2005), and rapid development (2006-2018); (2) By analyzing the citations of high-yield authors, institutions, journals and papers in this field, it is clear that the developed countries such as the United States, Britain, and the Netherlands have significantly stronger research capabilities in this field; (3) By analyzing the co-occurrence of keywords and co-citation of the literature in this field, the research hotspots in this field are summarized as the relationship between energy supply and demand, energy use efficiency, the relationship between various household indicators and energy consumption, environmental protection, modeling and measurement; (4) In view of the reality, future works should pay more attention to the influence of micro-factors, regional energy consumption issues, and energy consumption of rural households.
\end{abstract}

Keywords: households; energy; consumption; bibliometrics analysis

\section{Introduction}

Since the outbreak of the oil crisis in the 1970s, the contradiction between energy supply and demand has become increasingly prominent. In addition to industrial energy consumption which accounts for a significant proportion of energy consumption, household energy consumption has attracted extensive interest [1-4]. According to the data compiled by the International Energy Agency (IEA) in 2019, more than $20 \%$ of the total energy consumption of various OECD countries was consumed by households, of which developed countries such as Britain reached more than $30 \%$ [5]. At the same time, the global warming caused by the increasing anthropogenic greenhouse gas (GHG) has been widely discussed, and many countries have set emission reduction targets to reduce carbon dioxide emissions in response to climate change [6,7]. The industrial energy demand of the European Union has been exceeded by the energy demand of residents, and the energy consumption of households in some economically developed countries has accounted for more than $20 \%$ with a rising trend. The rapid growth of residential household energy consumption and its important position in overall energy consumption have made it increasingly discussed in the field of energy 
economics. Considerable attention has been paid to household energy consumption in order to reduce carbon dioxide emissions. Since the 1970s, tremendous investigations in this research area have been done: Herendeen [8] has proven that poor households purchase approximately $65 \%$ of their energy needs by purchasing residential energy and automotive fuels, while $35 \%$ for wealthy households. In addition, urban life consumes about $15 \%$ less intensive energy than non-agricultural life in rural areas. The research of Pachauri and Spreng [9] ascribed the increase in household energy demand in India to the increasing population; Wang [10] selected eight typical counties in the eight major economic zones of China through sample collection analysis and found that the local social environment, economic development level, availability of local resources, local residents' living habits, climate conditions, and other factors have a greater impact on the energy consumption of rural households; Baiocchi et al. [11] investigated and studied both direct and indirect carbon dioxide emissions of consumer behaviors in different British lifestyles, and concluded that consumer behaviors and lifestyles have a significant impact on British carbon dioxide emissions. In order to realize the sustainable use of energy, household energy conservation, building energy conservation, energy conservation behavior, and other related aspects around household energy consumption also generated considerable research interest. For example, Fertahi et al. [12] carried out various dynamic simulations on the thermal performance of the collective hot water production system, and found that the Evacuated Tube Technology (ETC) is suitable for this collective hot water production application, and increasing the centralized storage tank volume enhances the annual solar fraction of the collective hot water process. Pochwat et al. [13] compared two-prototype near-horizontal drain water heat recovery units on the basis of effectiveness, and proposed a method to improve the utilization rate of hydrothermal energy. Mathewset al. [14] compared four different energy savings measures and compared their payback periods in order to ascertain the most effective measures for a consumer's budget.

In addition, reviews related with different areas of household energy consumption have also been done. Kastner et al. [15] reviewed the empirical research on energy investment of 26 households, and made a detailed analysis of energy-related investment decisions and beliefs on the consequences for households, as well as access to energy consulting and financial incentives; Oladokun et al. [16] used a literature review to explore the evolution of the household energy consumption and carbon emission (HECCE) modeling paradigm in recent years, and derived these two main methods and methods used in modeling HECCE problems, which are econometrics and building physical statistics, and made a detailed analysis of the limitations in modeling technology. Abrahamse et al. [17] explore and evaluate previous interventions that encouraged families to reduce energy consumption, and discuss the relationship between information, knowledge, behavior, rewards, and energy savings. As a tool for quantitative analysis of literature, bibliometric methods have been widely used to evaluate the performance of various disciplines [18,19]. Kiriyama, Sanz-Casado, Montoya, and other authors used bibliometrics to conduct a literature analysis on global nuclear energy, solar energy production, and consumption, and Spain's energy research to explore research overviews and trends in the field [20-22]. Cohen [23] made a study on the energy needs of 11 urban households in Brazil and found that the energy intensity paid by households decreases with income levels, and there are large differences between different regions The China Household Energy Report (2016) [24] pointed out that, in the total energy consumption of the United States, the living energy consumption of residents increased from $17.5 \%$ in 1949 to $21.7 \%$ in 2013, while industrial energy consumption increased from $46 \%$ in 1949 and fell to $32.3 \%$ in 2013. As China gradually completes the process of industrialization, the industrial energy consumption will gradually slow down as well as a decreasing trend in the total energy consumption. With the increase of people's income, the energy consumption of residents, including transportation, will increase as well. The energy demand will also gradually increase, and finally the total household energy consumption and its proportion will gradually increase.

It is beneficial and necessary to summarize and analyze the existing literature so as to understand the current situation, research hotspots, and future development trends of energy consumption research in households. In addition, finally promote the sustainability and efficiency of household 
energy consumption. As far as the authors know, there remains an ongoing challenge to identify this problem. To fill the existing research gaps, we have carried out the following work. First, we use bibliometric methods to study the latest research status and trends, including the number of articles, country distribution, productive authors and institutions, and article citations. Secondly, through co-word analysis and literature co-citation analysis, we find the hottest research topics in this field. Finally, based on the above results, some suggestions on the study of household energy consumption issues are given in the conclusion. In summary, this article describes the current research in the following aspects: (1) the first attempt to summarize and evaluate the research status and trends in the field of energy consumption of households; (2) Based on co-word analysis and literature co-citation analysis, clarify current research hotspots, summarize potential research directions, and contribute to future development and research progress; (3) Based on the existing literature, evaluate, analyze and discuss the research status of different countries in this field, we expect to make a contribution to the future development as well as the research progress of in household energy consumption field.

\section{Materials and Methods}

The data in this study were collected from the Science Citation Index Expanded (SCI-E) and Social Science Citation Index (SSCI) online version databases compiled by Thomson Reuters. We first searched the SCI-E database and SSCI database for all types of keywords including "residential households", "energy", and "consumption" in all years. The first international journal papers on household energy consumption appeared in 1970 and the second appeared in 1976. A small number of related literature gradually appeared after 1980. Therefore, this article focuses on the period from 1980 to 2018. During these years, three types of subject words were searched, and a total of 4659 articles were retrieved. The retrieval time is 7 April 2019.

First of all, this study analyzes the number of articles and the distribution of countries, productive authors, institutions, and the strength of different countries in different periods to understand the development of household energy consumption, which is helpful for policies makers and researchers to make clear of professional research institutions and authors in the rapidly developing countries. Secondly, the co-word analysis and literature co-citation analysis are used to study the research hotspots and trends in this field in detail, and to provide some reference conclusions for scholars' future research choices.

\subsection{Collaboration Degree}

Collaboration in academic research indicates that the researchers working together for a common goal on the bases of common research needs [25]. Auctorial, institutional, and national collaboration degree are usually used to study the academic collaboration in a certain research area [26-28]. To analyze the literature co-authoring situations at different times, this study divides the index of literature co-authoring into three directions: author, country, and institution. The cooperation status of each point is expressed by the number of authors, countries, and institutions in the article. The cooperation in this field can be expressed by the average of the authors, institutions, and countries involved in all articles in the field. The formula is as follows:

$$
\begin{gathered}
\text { Auctorial collaboration degree : } \mathrm{C}_{1}=\frac{\sum_{i=1}^{\mathrm{N}} \alpha_{i}}{\mathrm{~N}}, \\
\text { Institutional collaboration degree : } \mathrm{C}_{2}=\frac{\sum_{i=1}^{\mathrm{N}} \beta_{i}}{\mathrm{~N}}, \\
\text { National collaboration degree : } \mathrm{C}_{3}=\frac{\sum_{i=1}^{\mathrm{N}} \gamma_{i}}{\mathrm{~N}},
\end{gathered}
$$

where $\mathrm{N}$ represents the number of all articles in the field, and $\alpha_{i}, \beta_{i}, \gamma_{i}$ represent the number of authors, institutions, and countries for article $i$. 


\subsection{Comprehensive Strength}

The international influence and international rankings of a country's academic field are influenced by multiple indicators. These influence indicators relate to the country's outstanding performance in this field, including authors, journals, number of papers, frequency of cited papers, etc. This study refers to the evaluation indicators in related literature [26], and analogously selects the number of papers, high-yielding authors (TOP100), high-yielding institutions (TOP100), high-cited papers (TOP100), high cited authors (TOP100), and high cited institutions (TOP100) in the country's household energy consumption field to reflect the country's international status in this field.

We calculate the corresponding standard score of each indicator in each country using the standard score statistics method. The specific calculation method is as follows:

$$
\begin{gathered}
\mathrm{S}_{i j}=\frac{\mathrm{x}_{i j}-\overline{\mathrm{x}_{j}}}{\sqrt{\frac{\sum_{i}\left(\mathrm{x}_{i j}-\overline{\mathrm{x}_{j}}\right)^{2}}{\mathrm{~T}}}}+1, \\
\mathrm{~S}_{i}=\sum_{j} \mathrm{~S}_{i j},
\end{gathered}
$$

where $S_{i j}$ represents the standard score of the $j$ th indicator in the $i$ th country; $x_{i j}$ represents the original score of the $j$ th indicator of the $i$ th country; $\overline{x_{j}}$ stands for the average score of all countries of the $j$ th indicator; $T$ represents the total number of countries; and $S_{i}$ represents the comprehensive score of the $i$ th country.

\subsection{Co-Word and Co-Cited}

The co-word analysis method was first proposed by Callon, a French bibliometrician, to determine the relationship between topics by focusing on the common occurrence of vocabulary pairs and name phrases in the literature [29]. The topic words in the paper are used as statistical objects, and the number of times that different topic words appear in the same paper is used to form a common word network composed of noun phrases or word pairs. In addition, the evacuation distance of the subject content is reflected by the distance between routines within the network. The co-word clustering analysis in this paper is mainly based on Citespace software (v_5.0.R4), which is used to identify and display new trends in scientific literature. In addition, Citespace is a citation visualization analysis software developed gradually under the background of scientometrics and data visualization. Through the co-occurrence of keywords, dynamic evolution, collection, and analysis of important nodes in network relationships, the hotspots and development processes of residential energy consumption can be concluded. The size of the nodes in the graph indicates how often the keywords appear. The higher the keyword's appearance frequency, the larger the node, which also means stronger centrality. The connection between the nodes indicates the common appearance of the keyword [30,31].

Cited references refer to two articles cited by the same reference. By analyzing the clusters and key nodes in the co-citation network, it is possible to reveal the knowledge structure, knowledge base, evolution of the research front, and the literature that played a key role in the evolution process. In this paper, we use the Citespace software to draw a co-cited clustered time zone view map of the literature on the energy consumption of households in order to discover the knowledge base in this field and the evolution of the research front. Based on this, an inductive summary is made to predict future research directions. The nodes in the figure represent the article needing to be analyzed, and the size of the nodes corresponds to number of citations of this article. The color and width of the inner circle of the nodes show the frequency of being cited in different periods. The connection between the nodes indicates the co-citation relationship. The degree of width shows the intensity of co-citation, and the different colors correspond to the time of the first co-citation. The change in color from cold to warm, i.e., from blue to red, represents a change in time from early to recent $[30,32]$. 


\section{Results}

\subsection{Number of Publications by Countries}

The 4659 articles in the search results are from 127 countries. Figure 1 lists the trends in publications in the 10 countries with the highest number of publications. It can be seen that international research on household energy consumption is roughly divided into three development stages: the cognitive stage from 1970 to 1990, the inquiry stage from 1991 to 2005, and the rapid development stage from 2006 to now. During the inquiry stage, the study from British and American was in a leadership position. With the break out of the Gulf War in 1991 and the implementation of the 1992 Energy Policy Act by the US Congress which requires the energy-related departments should improve energy efficiency standards when formulating policies. All of these have promoted the development of research about residents' energy consumption in this period. During the rapid development stage, international scholars' enthusiasm for research on household energy consumption has grown rapidly, with an average annual increase of $23.23 \%$ in number of published papers. According to the Global Energy Balance Sheet of the IEA, the global energy consumption by residents accounted for $21.24 \%$ of total energy consumption, while industrial energy consumption accounted for $29.03 \%$ of total energy consumption in 2017 [5].

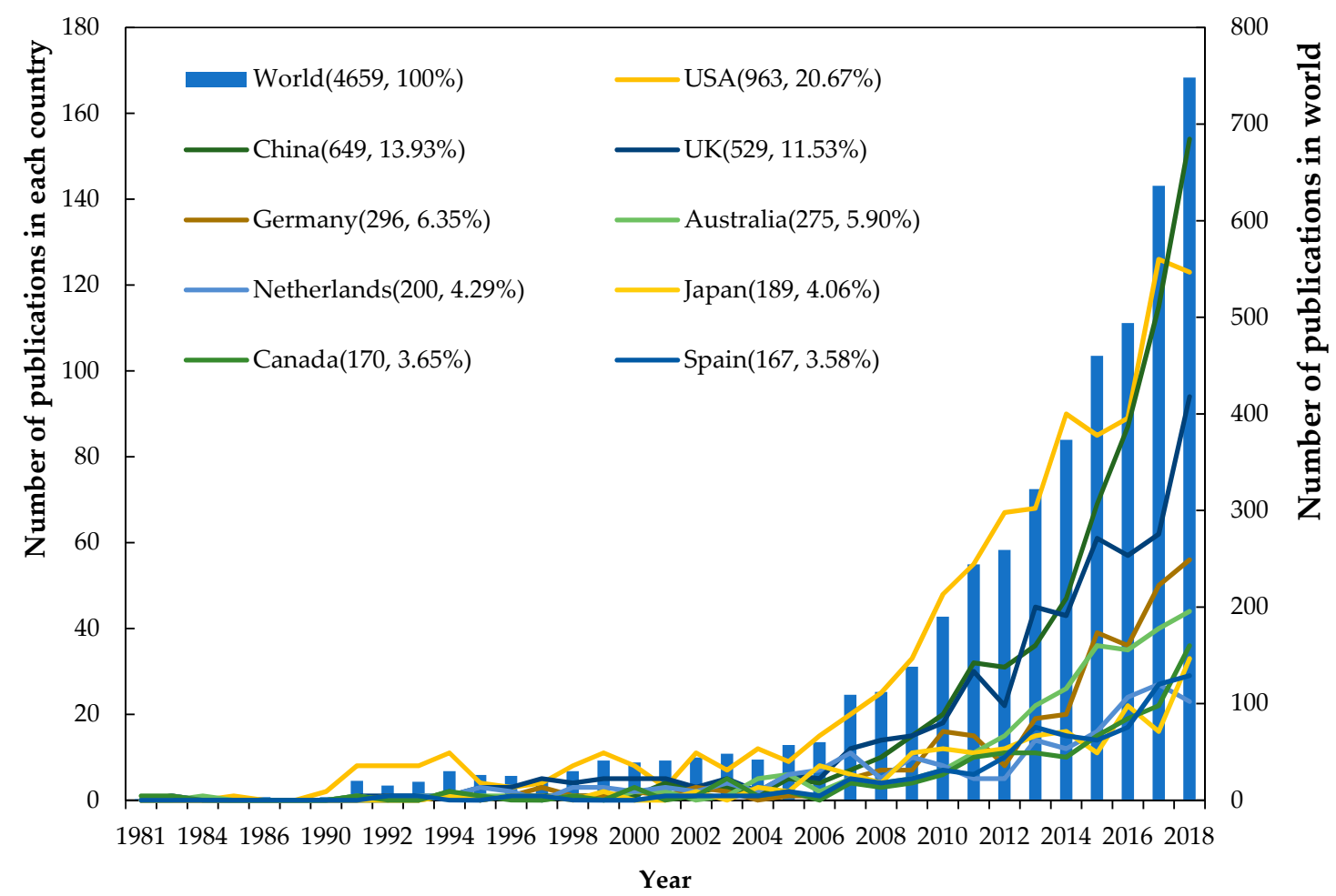

Figure 1. Timeline of publications in top 10 productive countries in the field of household energy consumption where China excludes Taiwan and the United Kingdom includes England, Scotland, Northern Ireland, and Wales. Source: SCI-E and SSCI online version databases.

\subsection{Author Statistics}

Based on the statistics on the search results of authors in this field, there are 8102 authors in total. The eminent scientific historian, Price, concluded that, in the same subject, half of the number of papers were written by highly productive authors, whose collective number is approximately the square root of the total number of authors in the subject of the field [33,34]. That is Price's law, which is expressed by the formula: $\approx 0.749 \times \sqrt[2]{\mathrm{n}_{\max }}: \mathrm{m}$ is the minimum number of publications of core scientists in the subject area. $\mathrm{n}_{\max }$ represents the number of publications of the most productive scientist. The Price's 
law can be verified as follows: the highest number of papers published by the scientist is $\mathrm{n}_{\max }=27$, and the minimum number of papers is obtained by substituting $n_{\max }$ into Price's law and $m=3.89$. In the search results, 426 scholars published four or more articles in this search area, and the total number of papers published by these authors was 2429 , accounting for $54.28 \%$ of the total literature in this field, which basically complied with Price's law. Table 1 shows the top eight authors with the most published papers. It can be seen that the most productive authors are mainly in Brazil (3 persons), the United States, Germany, China, the United Kingdom, and Malaysia.

Table 1. Productive authors during 1980-2018.

\begin{tabular}{ccccccc}
\hline Rank & Authors & Country & TP & CF & CPP & Article \\
\hline 1 & Popkin & USA & 27 & 51 & 1.89 & {$[35]$} \\
2 & Stamminger & Germany & 25 & 91 & 3.64 & {$[36]$} \\
3 & Levy & Brazil & 20 & 105 & 5.25 & {$[37]$} \\
4 & Claro & Brazil & 19 & 95 & 5.00 & {$[38]$} \\
5 & Monteiro & Brazil & 19 & 88 & 4.63 & {$[37]$} \\
6 & Hubacek & England & 15 & 235 & 15.67 & {$[39]$} \\
7 & Wang & China & 15 & 171 & 11.40 & {$[40]$} \\
8 & Masjuki & Malaysia & 14 & 60 & 4.29 & {$[41]$} \\
\hline
\end{tabular}

Note: TP is the number of total publications; CF is Cited Frequency; CPP is citations per publication; this paper adds some articles of higher quality for each author to help identify authors or add more information about them.

\subsection{Institution Statistics}

In addition, 4659 articles come from 3581 institutions. Table 2 shows the top 10 institutions with the most published literature in this field (the 10th and 11th names are tied). The institution with the most papers in the field of residential energy consumption is the Chinese Academy of Sciences, accounting for $1.95 \%$ of the world's papers in this field. However, among the top ten countries and regions with high-yielding institutions, the number of developed countries is significantly higher than that of developing countries. Developed countries such as the United Kingdom and the United States have four and two institutions, respectively. Three institutions in China have a higher volume of papers.

Table 2. Productive institutions during 1980-2018.

\begin{tabular}{ccccccc}
\hline Rank & Institution & Countries & TP & CF & TP RC (\%) & TP RW (\%) \\
\hline 1 & Chinese Acad Sci & China & 91 & 399 & 14.02 & 1.95 \\
2 & Univ Cambridge & England & 62 & 260 & 11.72 & 1.33 \\
3 & Univ Calif Berkeley & USA & 57 & 294 & 5.92 & 1.22 \\
4 & Tsinghua Univ & China & 55 & 169 & 8.47 & 1.18 \\
5 & Univ Sao Paulo & Brazil & 54 & 126 & 41.54 & 1.16 \\
6 & Univ N Carolina & USA & 51 & 66 & 5.30 & 1.09 \\
7 & Univ Leeds & England & 45 & 290 & 8.51 & 0.97 \\
8 & Beijing Inst Technol & China & 39 & 285 & 6.01 & 0.84 \\
9 & UCL & England & 38 & 146 & 7.18 & 0.82 \\
10 & Delft Univ Technol & Netherlands & 36 & 176 & 18.00 & 0.77 \\
11 & Univ Oxford & England & 36 & 128 & 6.81 & 0.77 \\
\hline
\end{tabular}

Note: TP is the number of total publications; CF is Cited Frequency; RC is the percentage of the total number of the publication to that of its country; RW is the percentage of the total number of the publication to that of the world.

\subsection{Academic Collaboration}

By collating the data of 4659 documents retrieved from this field into the above Equations (1)-(3), we can find that the collaboration degree among the authors, institutions, and countries in this field are $2.85,1.66$, and 1.15 , respectively. Calculating the data of the three indicators for each year from 1980 to 2018 and making a line chart (Figure 2). It can be seen that the degree of collaboration at the national level has increased year by year since 2000, and the degree of institutional collaboration has also shown an overall upward trend, while the auctorial collaboration degree has increased alternately from beginning to end. 


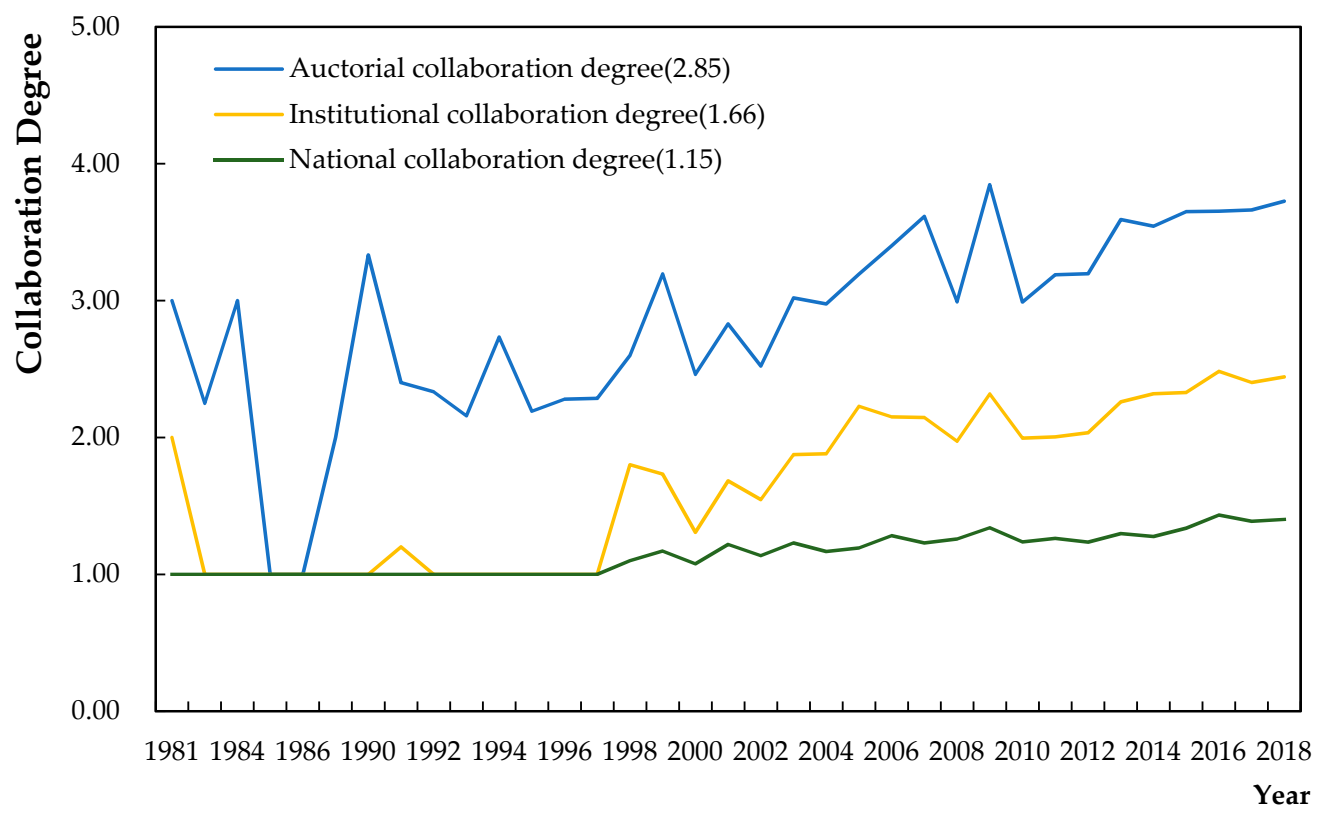

Figure 2. Three levels of collaboration degrees, 1980-2018.

\subsection{National Comprehensive Strength in the Field of Household Energy Consumption}

According to Equations (4) and (5), various indicators and comprehensive scores of household energy consumption in TOP100 countries were calculated as shown in Table 3. The top country is the United States with a combined score of 24.52, followed by China and the United Kingdom. The fourth place Netherlands accounts for half of the British's total score, while it accounts for only one third of the United States' total score.

Table 3. The national comprehensive strength (Top 10).

\begin{tabular}{|c|c|c|c|c|c|c|c|c|c|c|c|c|c|c|c|c|}
\hline \multirow{2}{*}{ Rank } & \multirow{2}{*}{ Countries } & \multicolumn{2}{|c|}{ TP } & \multicolumn{2}{|c|}{ Authors } & \multicolumn{2}{|c|}{$\mathbf{I}$} & \multicolumn{2}{|c|}{ TMPC } & \multicolumn{2}{|c|}{ TMAC } & \multicolumn{2}{|c|}{ TMIC } & \multicolumn{2}{|c|}{ TC } & \multirow{2}{*}{ TSS } \\
\hline & & $\mathrm{X}$ & $\mathrm{S}$ & $x$ & $\mathrm{~S}$ & $x$ & $S$ & $x$ & $\mathrm{~S}$ & $x$ & $\mathrm{~S}$ & $x$ & $\mathrm{~S}$ & $X$ & $S$ & \\
\hline 1 & USA & 963 & 4.21 & 9 & 1.44 & 21 & 3.78 & 18 & 3.22 & 19 & 3.42 & 33 & 4.78 & 3300 & 3.67 & 24.52 \\
\hline 2 & China & 649 & 2.83 & 45 & 5.11 & 18 & 3.27 & 7 & 1.41 & 12 & 2.25 & 7 & 1.34 & 2208 & 2.46 & 18.67 \\
\hline 3 & UK & 529 & 2.30 & 7 & 1.23 & 11 & 2.08 & 20 & 3.55 & 16 & 2.92 & 14 & 2.26 & 2690 & 2.99 & 17.34 \\
\hline 4 & Netherland & 200 & 0.86 & 4 & 0.93 & 3 & 0.71 & 15 & 2.73 & 0 & 0.24 & 7 & 1.34 & 1817 & 2.03 & 8.83 \\
\hline 5 & Australia & 275 & 1.19 & 4 & 0.93 & 9 & 1.73 & 3 & 0.75 & 5 & 1.08 & 3 & 0.81 & 992 & 1.12 & 7.61 \\
\hline 6 & Norway & 94 & 0.39 & 2 & 0.72 & 2 & 0.54 & 7 & 1.41 & 14 & 2.58 & 1 & 0.54 & 632 & 0.73 & 6.92 \\
\hline 7 & Germany & 296 & 1.28 & 2 & 0.72 & 5 & 1.05 & 3 & 0.75 & 1 & 0.41 & 7 & 1.34 & 993 & 1.12 & 6.68 \\
\hline 8 & Brazil & 130 & 0.55 & 7 & 1.23 & 4 & 0.88 & 1 & 0.42 & 6 & 1.24 & 3 & 0.81 & 409 & 0.48 & 5.62 \\
\hline 9 & Japan & 189 & 0.81 & 3 & 0.83 & 6 & 1.22 & 3 & 0.75 & 0 & 0.24 & 2 & 0.68 & 900 & 1.02 & 5.55 \\
\hline 10 & Canada & 170 & 0.73 & 2 & 0.72 & 3 & 0.71 & 1 & 0.42 & 7 & 1.41 & 2 & 0.68 & 550 & 0.64 & 5.31 \\
\hline
\end{tabular}

Note: TP is the number of total publications; I indicates the number of institutions; TMPC is the number of total most cited papers' citations; TMAC is the number of total most cited authors' citations; TMIC is the number of total most cited institutions' citations; TC is the number of total citations; TSS is the total standard score; $\mathrm{S}$ is Standard score in this section; TSS is the sum of standard scores.

\subsection{Co-Word and Co-Cited Analysis}

Keywords represent hot research topics, and sudden words represent new research frontiers. Keyword analysis can help us find hot topics and research frontiers. In the literature published in the field of residential household energy consumption from 1980 to 2018, the frequency of occurrence of all keywords in the same literature was counted in pairs, and cluster analysis was used to analyze the co-occurrence matrix. After statistics on the keywords of all articles, in 4659 documents, the results show that there are 42 keywords that appear more than 100 times. This article mainly analyzes the literature of the last two stages of the field development, namely 1991-2018. The keywords in the second and third stages are co-word clustered respectively. By using Citespace software, we get the 
keyword clustering views of Figure 3; Figure 4 in the two stages of 1991-2005 and 2006-2018. There are 16 clusters in the clustering Figure 3 formed by the literature keywords from 1991-2005, and 14 clusters in the Figure 4 formed by the literature keywords from 2006-2018. The log-likelihood rate (LLR) algorithm is used to extract the names of the clusters. Here, only the 10 clusters in the previous stage and the seven clusters in the latter stage are shown here.

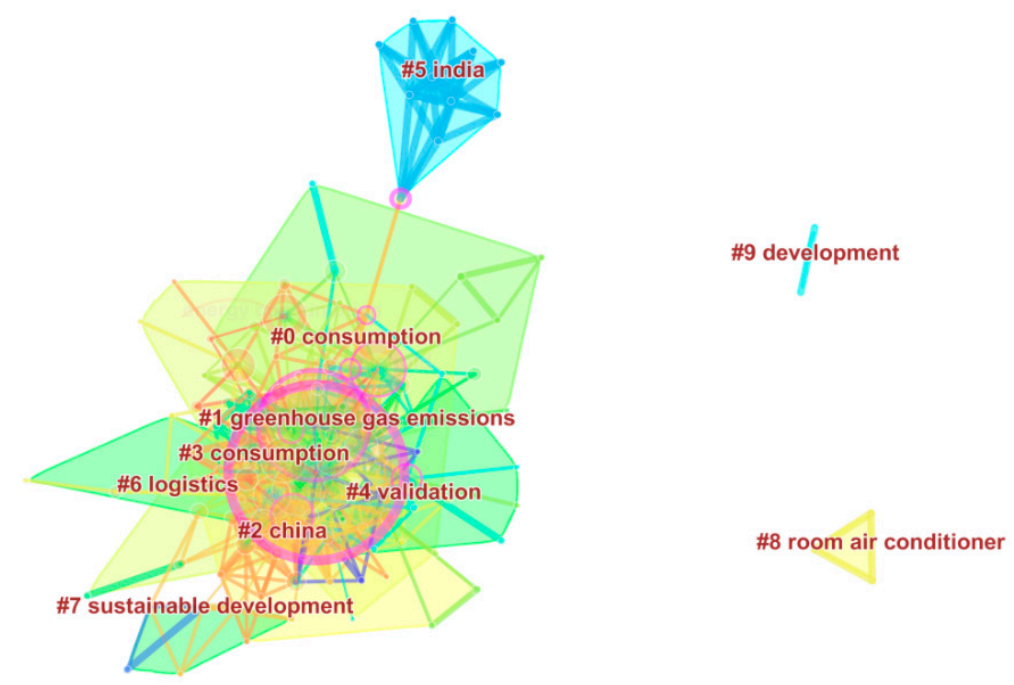

Figure 3. Keyword clustering diagram of literature on energy consumption in residential households, 1991-2005.

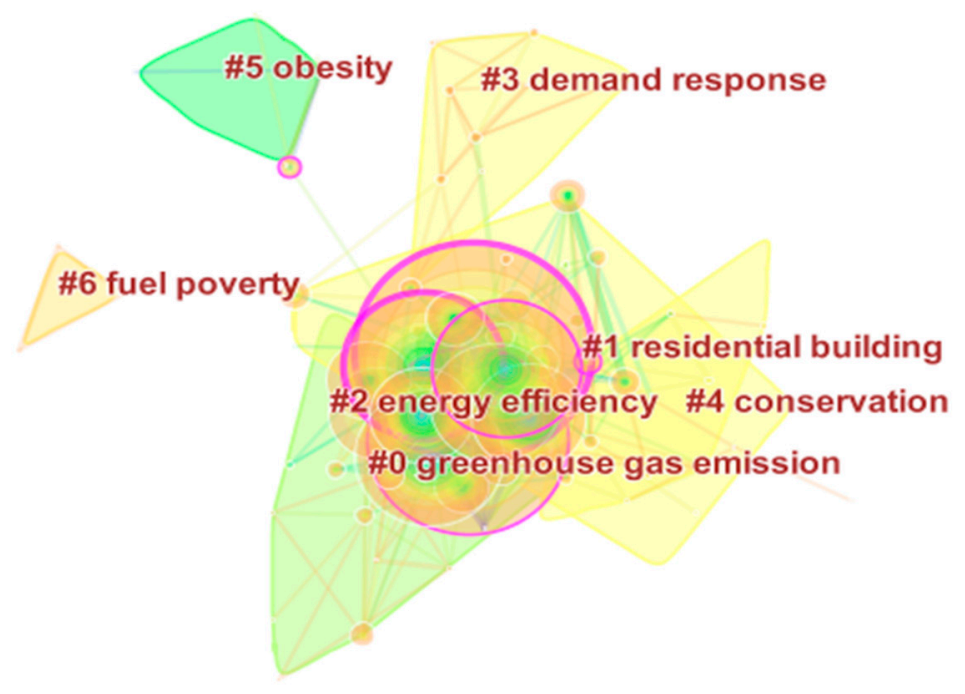

Figure 4. Keyword clustering diagram of literature on energy consumption in residential households, 2006-2018.

The cited literature reflects the source of knowledge, and the representative articles in each cluster reflect the frontier of this field. In this paper, we use the Citespace software to draw the citing clustered time zone view map of the literature from 1991 to 2018 in the field of household energy consumption, as shown in Figure 5. Selecting named terms from the title of the literature and using the LLR algorithm to select the naming of the cluster tags, the results are 58 clusters. Here, the top 15 major clusters are selected for analysis. 


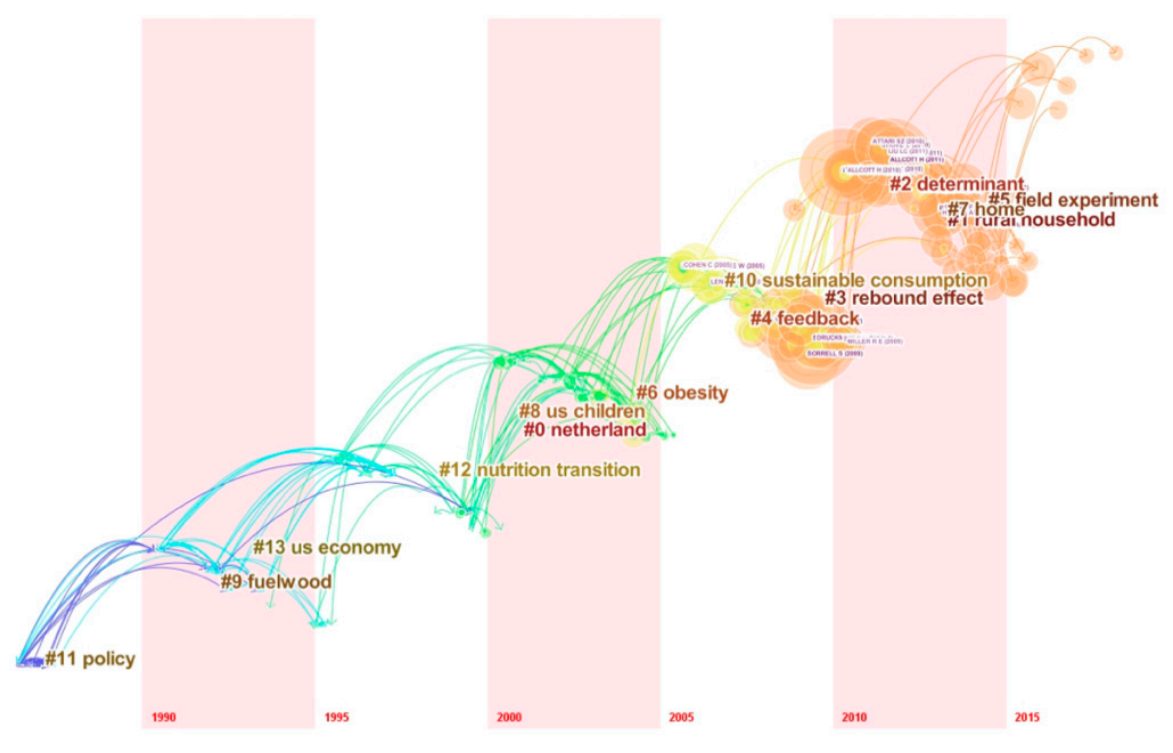

Figure 5. Co-citation clustering time zone view of literature on household energy consumption, 1991-2018.

\section{Discussion}

According to previous results in Part 3, the research and development of household energy consumption can be divided into three stages: the cognitive period, the inquiry period, and the rapid development period. According to the analysis results of Author Statistics, Institution Statistics, and Academic collaboration, we know that countries that have developed rapidly in this field include the United States, China, and the United Kingdom, and authors and institutions in developed countries account for the majority. The future work should focus on the cooperation between countries, institutions, and authors.

From the comprehensive strength in this field, the scientific research capabilities are all developed countries in Europe and the United States excepting China as a developing country in the top ten. With the exception of high-yielding authors, most indicators in the field in the United States are two to three times that of other countries. Furthermore, from the perspective of quantity (high production number) and qualitative (cited number), China is relatively competitive in high-yield authors compared with other countries while less competitive at both the number of papers and high-yield institutions. The other four indicators are also in a relatively weak position; in particular, the number of highly cited papers is less than the overall average of the indicator, and the weak value of the cited index also reflects that the quality of Chinese literature in this field needs to be improved. Finally, from the perspective of institutions, authors, and papers, the United States has an advantageous competitiveness in institutions with strong scientific research capacity in this field, and the number of authors and papers in China is superior to quality, which indicates that the development of the organization has a significant boost to the improvement of scientific research strength in this field. The impact of the quality of literature on the improvement of the country's overall strength is greater than the impact of quantity on it. In addition, it is worth noting that the size of the countries can also affect the research in this field. The top ten countries in the comprehensive strength in this field are almost developed or big countries with great power. It is obvious that the overall scientific research strength of these countries is relatively strong. On the one hand, the United States, China, Britain, Australia, and so on, with a strong economic strength can provide a solid financial support for research related to household energy consumption. On the other hand, issues in household energy consumption in these large countries are very urgent and the problem of energy shortage is more prominent, which also puts forward more requirements on the research in household energy consumption. 
In terms of the analysis of research hotspots, the evolution of research frontiers, and the potential research areas about household energy consumption, Detailed investigations were made on the co-word analysis as shown in Figures 3 and 4. Based on the analysis of clustering results, the research hotspots in the two stages are shown in Tables 4 and 5.

Table 4. Research hotspots of household energy consumption, 1991-2005.

\begin{tabular}{cclc}
\hline Cluster \# & Label & \multicolumn{1}{c}{ Main Research Content } & $\begin{array}{c}\text { Representative } \\
\text { Literature }\end{array}$ \\
\hline 0 & Consumption & $\begin{array}{l}\text { Biofuel consumption, electricity } \\
\text { consumption, consumption patterns and } \\
\text { energy intensity }\end{array}$ & {$[42,43]$} \\
\hline 1 & GHG emission & $\begin{array}{l}\text { Energy saving in refrigerators, gasoline } \\
\text { prices and taxes, household energy use }\end{array}$ & {$[44,45]$} \\
\hline 2 & China & $\begin{array}{l}\text { Household energy consumption, } \\
\text { rural residents }\end{array}$ & {$[46,47]$} \\
\hline 3 & Consumption & Residents' health, food consumption & {$[48,49]$} \\
\hline 4 & Validation & Healthy diet & {$[50,51]$} \\
\hline 5 & India & $\begin{array}{l}\text { Population, direct and indirect } \\
\text { energy consumption }\end{array}$ & {$[9,52]$} \\
\hline 6 & Logistics & Power consumption & {$[53]$} \\
\hline 7 & Sustainable development & $\begin{array}{l}\text { Sustainable development, low-carbon } \\
\text { economy, rural Emission reduction, } \\
\text { regional development }\end{array}$ & {$[54,55]$} \\
\hline 8 & Room air condition & Residential building, life cycle & {$[56,57]$} \\
\hline 9 & Development & Economic development, energy demand & {$[58,59]$} \\
\hline
\end{tabular}

Table 5. Research hotspots of household energy consumption, 2006-2018.

\begin{tabular}{cccc}
\hline Cluster \# & Label & Main Research Content & $\begin{array}{c}\text { Representative } \\
\text { Literature }\end{array}$ \\
\hline 0 & GHG emission & $\begin{array}{c}\text { Natural gas, electricity consumption, } \\
\text { household income }\end{array}$ & {$[11,60]$} \\
\hline 1 & Residential building & $\begin{array}{c}\text { Household income, GHG, energy } \\
\text { consumption patterns }\end{array}$ & {$[61,62]$} \\
\hline 2 & Energy efficiency & $\begin{array}{c}\text { Rebound effect, residential behavior, } \\
\text { energy supply and demand }\end{array}$ & {$[63]$} \\
\hline 3 & Demand response & $\begin{array}{c}\text { Home energy management, household } \\
\text { behavior }\end{array}$ & {$[64,65]$} \\
\hline 5 & Conservation & $\begin{array}{c}\text { Home energy saving, environmental } \\
\text { protection }\end{array}$ & {$[66,67]$} \\
\hline 6 & Obesity & Healthy diet & {$[68,69]$} \\
\hline
\end{tabular}

In the keyword clustering from 1991 to 2005, cluster \#0 "consumption" mainly involves research on biofuel consumption, electricity consumption, residential buildings, consumption patterns and energy intensity, and regional energy planning. The label of cluster \#3 is also consumption while the main research object under this cluster is food consumption, which is mainly reflected in the related aspects of residents' health and diet. The main research object of cluster \#1 "GHG emission" is refrigerator energy savings, gasoline price and gasoline tax, residential energy consumption model, and household energy consumption, which is suggested to reduce residents' energy consumption through various channel models. Cluster \#2 and Cluster \#5 explore the energy consumption of households in China and India, respectively. China and India both have special national conditions, i.e., a large scale of populations. The impact of the amount is worth exploring. The central points in Figure 3 are "consumption", "energy requirement", "energy use", "model”, and "nutritional status", "Children", 
"energy efficiency", "fuel wood", etc. From these central nodes, it can be concluded that there are three main research directions in the field of energy consumption of households from 1991 to 2005: energy supply and consumption, healthy diet consumption, and energy and development.

In the keyword clustering from 2006 to 2018, cluster \#0 "GHG emission" contains relevant research content including natural gas, electricity consumption, and residents' income, which is usually regarded as the main influence factor of GHG emission; Cluster \#1 "residential building" also touches importance on topics such as income and GHG; the research contents of energy use is reflected in clusters \#2 and 3, including rebound effects, residential behavior, and energy management. Research on energy use can clarify the impact of human factors on energy efficiency and promote the sustainability of household energy consumption; it can be seen from the keywords of cluster \#4 that the topic of energy conservation and environmental protection has attracted more and more attention, which can promote the "Ecological Civilization"; cluster \#5 is related to food health consumption such as diet health, sugar intake, and obesity. Broadly speaking, household energy consumption involves people's common life, including food, clothing, transportation, etc. Thus, there exists a relationship between energy consumption and human health, for example, obesity. Previous studies have proven that the lifestyle of relying on a car instead of walking may result in obesity and then affect household energy consumption [71,72]. In another way, the search results may include results of energy intake of human being, mixing household energy consumption with human energy intake. However, this does not affect the final result significantly. The keywords at this stage are: GHG emission, residential building, energy efficiency, household behavior, environment, etc. Through the content analysis of each clustering result, it can be proved that the research direction at this stage is mainly reflected in GHG emissions, the relationship between household income and residents' behavior and energy consumption, environmental protection, modeling and measurement, etc.

Comparing the keywords co-occurrence clustering map from 1991-2005 to 2006-2018, we can see the development and changes of research hotspots. The previous research hotspots mainly focused on energy itself, for example, how to improve energy efficiency and how to enhance the relationship between energy supply and demand to improve family living standards and ultimately achieve the purpose of promoting social progress. The research hotspots of the latter stage are mainly focused on the research of relationships and influences, which added new hotspot studies such as the analysis of household income and the analysis of individual residents' behavior. At the same time, the topic of environmental protection has been more emphasized, which is specifically reflected in the relationship between household income and energy consumption, the relationship between socioeconomic development and environmental protection, and the impact of household income, residents' behavior, and consumption patterns on energy consumption. The main research methods involve input-output analysis and life-cycle assessment methodology [8,73-75], which are mostly reflected in model construction and improvement.

The time zone view shows the growth of the cited documents in different time zones by placing nodes in different time zones according to the first cited time of the document. From the time zone view (Figure 5), it can be seen that the literature on the energy consumption of households grew slowly from 1980 to 1990, and increased fast from 1991 to 2005. The results from 2006 to the present are fruitful. The results of the development process found in this field are consistent. It also can be found that the development and evolution of the household energy consumption field originated to some extent from the research and recommendations of national policies. After that, scholars paid more attention to energy consumption and residents' health. It is worth noting that the important rebound effect proposed at the end of the 20th century has become a research hotspot in the past decade. That is, the energy saved by energy efficiency improvement may be partially offset by the new energy demand generated by a series of rebound mechanisms such as substitution effect, income effect, and output effect. In recent years, even in the future, research hotspots may be on the research of household energy consumption in rural areas or between rural residents, including the behavior of residents, environmental protection, and household energy management. 
In view of the development and evolution of the cited documents (Figure 5), a representative research in the early research cluster \#13 US economics is the analysis of the impact of incentives related to consumption tax on alcohol fuel on the US economy and environmental benefits [76], which can be essentially attributed to the research on energy itself. From the name of clusters \#0, \#1, \#8, and \#13, it can be seen that these all related with regional characteristics. Chinese scholar Zha Donglan [77] using the logarithmic average Divisia index decomposition method to explore the factors that may affect the change of carbon dioxide emissions from China's residential energy consumption. Duarte [78] analyzed the impact of Spanish household consumption patterns on pollution emissions, and Ekholm [79] analyzed the determinants of rural household energy consumption in India. The regional characteristics in these studies showed the trend of regionalization and meticulous in the research in household energy consumption. On the one hand, scholars from various countries concentrate on exploring the domestic energy economic situation and provide policy suggestions for the development of their own society. On the other hand, the much more convenient and fast data acquisition in their own countries provides a supporting basis for targeted research. The cluster \#3 rebound effect is mainly based on the theories issued by Peter [80], i.e., technological progress makes equipment more energy-saving. Under the same other conditions, as equipment becomes more energy-saving, the capital per unit of equipment service decreases because people tend to generate additional productive service needs, which also means additional energy consumption, called the rebound effect. The rebound effect shows that $10 \%$ of the increase in energy utilization due to technological development is offset by an increase in consumption. According to the node size, color and thickness in the circle of cluster \#3 in Figure 5, after the self-rebound effect was put forward, scholars paid more attention to this effect year by year and conducted a lot of scientific research, including consumption and rebound effect from the perspective of industrial ecology, energy utilization rate of consumer terminals and rebound effect, direct and indirect rebound effect estimation of household energy efficiency, and so on $[81,82]$. Furthermore, the cluster \#5 field experiment has also been a hot research trend in this field in recent years. This cluster mainly focuses on household energy conservation and empirical research. The influential document is Fischer's [83] research on electricity consumption feedback. Through the psychological model, Fischer explored which kind of electricity consumption feedback can better control customers' consumption and ultimately save energy. The results showed that successful feedback is often frequent, long-term, and interactive. The other two more valuable research works are Carrico's [84] research on motivating energy conservation in the workplace and Asensio's [85] research on the effectiveness of non-price information strategies in stimulating energy conservation.

Judging from the overall development and evolution of residential household energy consumption research, we find that the research basis in this field is environmental climatology, social psychology, statistics, economics and other disciplines, and scholars' research on household energy has gradually changed from macro climate and environmental changes and energy consumption (coal, oil, natural gas, electricity, etc.) to micro residents behavior, energy conservation awareness, and regional consumption level exploration. It is more in-depth and detailed from the whole to the partial in the process of development, and the focus is on the rebound effect, GHG emissions, residents' behavior, urban and rural households, energy conservation, consumption patterns, and factor exploration.

\section{Conclusions}

This study used bibliometric methods to summarize the research on household energy consumption from 1970 to 2018. Firstly, international research on household energy consumption is divided into three stages, and the research hotspots and developments in this field can be summarized as two important stages. From 1991 to 2005, research hotspots in household energy consumption were energy supply and consumption, energy efficiency, and healthy diet consumption; research hotspots transferred into GHG emissions, the relationship between household income and energy consumption, environmental protection, modeling and metering, etc. since 2006. In addition, the co-word analysis and co-citation analysis indicate that research directions in this field in the future might be factor 
exploration. Furthermore, in terms of international cooperation, the degree of collaboration among authors, institutions, and countries in the field of household energy consumption is $2.68,1.83$, and 1.25, respectively. There need more opportunities for cooperation in the future. Finally, countries with strong research strength in the research field of energy consumption of households include the United States, Britain, China, the Netherlands, Japan and other countries.

There still remain some challenges in the field of household energy consumption, and it is worthwhile devoting much effort, although the number of scientific research is relatively large while the quality is relatively low. The degree of international cooperation in this field is also relatively low, especially the cooperative relations between countries and institutions. Therefore, it is suggested that, while developing the research field of energy consumption of households, the quality of research results should also be improved, and high-quality papers should be published, and high-quality scientific research institutions should be established. In addition, it is necessary to strengthen international cooperation in this field. It can enhance its cooperative relations from the three levels of scholars, institutions, and countries. This will greatly benefit institutions and scholars in their research capabilities and levels in this field. Secondly, scholars in this field are suggested to keep up with the international frontiers, and reveal the internal and external relations of energy consumption in accordance with the special national conditions and regional characteristics of each country. People intend to know how to achieve reasonable and efficient use of resources through external regulation and macro and micro control. In addition, key research can be done on household energy consumption within and between regions and rural household energy consumption, including aspects of residential behavior, environmental protection, and household energy management.

Author Contributions: Conceptualization, X.M., M.W., and C.L.; methodology, X.M. and M.W.; software, M.W.; formal analysis, M.W.; investigation, M.W. and C.L.; writing-original Chinese draft preparation, M.W. and C.L.; writing-English review and editing, C.L.; supervision, X.M.; funding acquisition, X.M. All authors have read and agreed to the published version of the manuscript.

Funding: This study is supported by the National Natural Science Foundation of China (NSFC) (Reference Nos. 71573015, 71303019 and 71521002) and the National Key Research and Development Program of China (2016YFA0602801).

Conflicts of Interest: The authors declare no conflicts of interest.

\section{References}

1. Hertwich, E.G.; Peters, G.P. Carbon Footprint of Nations: A Global, Trade-Linked Analysis. Technol. Environ. Sci. 2009, 43, 6414-6420. [CrossRef]

2. Stoppok, M. Of culture, consumption and cost: A comparative analysis of household energy consumption in Kenya, Germany and Spain. Energy Res. Soc. Sci. 2018, 40, 127-139. [CrossRef]

3. Xia, C.; Li, W.; Chang, X.; Delicato, F.C.; Zomaya, A. Computational Intelligence for Pervasive Systems. In Proceedings of the 4th International Conference on Big Data Intelligence and Computing and Cyber Science and Technology Congress (DASC/PiCom/DataCom/CyberSciTech), Athens, Greece, 12-15 August 2018.

4. Korzeniowska-Ginter, R. Energy consumption by cooking appliances used in Polish households. IOP Conf. Ser. Earth Environ. Sci. 2019, 214, 012096. [CrossRef]

5. World Energy Balances 2019. IEA (International Energy Agency), 2019. Available online: https://www.iea. org/data-and-statistics (accessed on 14 September 2019).

6. CCC. Building a Low-Carbon Economy-the UK's Contribution to Tacking Climate Change; Committee on Climate Change: London, UK, 2008.

7. Cong, R.G.; Wei, Y.-M. Experimental comparison of impact of auction format on carbon allowance market. Renew. Sustain. Energy Rev. 2012, 16, 4148-4156. [CrossRef]

8. Herendeen, R. Total energy cost of household consumption in Norway, 1973. Energy 1973, 3, 615-630. [CrossRef]

9. Pachauri, S. An analysis of cross-sectional variations in total household energy requirements in India using micro survey data. Energy Policy 2004, 32, 1723-1735. [CrossRef] 
10. Xiaohua, W.; Xianrong, H.; Ling, J. Study on rural household energy consumption in China based on household investigation from typical counties. Trans. Chin. Soc. Agric. Eng. (Trans. CSAE) 2014, 30, $206-212$. (In Chinese)

11. Baiocchi, G.; Minx, J.; Hubacek, K. The Impact of Social Factors and Consumer Behavior on Carbon Dioxide Emissions in the United Kingdom. J. Ind. Ecol. 2010, 14, 50-72. [CrossRef]

12. Fertahi, S.E.-D.; Jamil, A.; Kousksou, T.; Benbassou, A. Energy performance enhancement of a collective hot water production process equipped with a centralized storage tank. J. Energy Storage 2019, 25, 100849. [CrossRef]

13. Pochwat, K.; Kordana, S.; Starzec, M.; Słyś, D. Comparison of two-prototype near-horizontal Drain Water Heat Recovery units on the basis of effectiveness. Energy 2019, 173, 1196-1207. [CrossRef]

14. Mathews, G.E.; Mathews, E.H. A Cost Comparison of Different Energy Saving Measures in a Household. In Proceedings of the 2017 International Conference on the Domestic Use of Energy (DUE), Cape Town, South Africa, 4-5 April 2017.

15. Kastner, I.; Stern, P.C. Examining the decision-making processes behind household energy investments: A review. Energy Res. Soc. Sci. 2015, 10, 72-89. [CrossRef]

16. Oladokun, M.G.; Odesola, I.A. Household energy consumption and carbon emissions for sustainable cities-A critical review of modelling approaches. Int. J. Sustain. Built Environ. 2015, 4, 231-247. [CrossRef]

17. Abrahamse, W.; Steg, L.; Vlek, C.; Rothengatter, T. A review of intervention studies aimed at household energy conservation. J. Environ. Psychol. 2005, 25, 273-291. [CrossRef]

18. Du, H.; Li, B.; Brown, M.A.; Mao, G.; Rameezdeen, R.; Chen, H. Expanding and shifting trends in carbon market research: A quantitative bibliometric study. J. Clean. Prod. 2015, 103, 104-111. [CrossRef]

19. Cañas-Guerrero, I.; Mazarrón, F.R.; Calleja-Perucho, C.; Pou-Merina, A. Bibliometric analysis in the international context of the "Construction \& Building Technology" category from the Web of Science database. Constr. Build. Mater. 2014, 53, 13-25.

20. Kiriyama, E.; Kajikawa, Y.; Fujita, K.; Iwata, S. A lead for transvaluation of global nuclear energy research and funded projects in Japan. Appl. Energy 2013, 109, 145-153. [CrossRef]

21. Sanz-Casado, E.; Lascurain-Sánchez, M.L.; Serrano-Lopez, A.E.; Larsen, B.; Ingwersen, P. Production, consumption and research on solar energy: The Spanish and German case. Renew. Energy 2014, 68, 733-744. [CrossRef]

22. Montoya, F.G.; Montoya, M.G.; Gómez, J.; Manzano-Agugliaro, F.; Alameda-Hernández, E. The research on energy in spain: A scientometric approach. Renew. Sustain. Energy Rev. 2014, 29, 173-183. [CrossRef]

23. Cohen, C.; Lenzen, M.; Schaeffer, R. Energy requirements of households in Brazil. Energy Policy 2005, 33, 555-562. [CrossRef]

24. Zheng, X.; Wei, C. Household Energy Consumption in China: 2016 Report; Springer: Singapore, 2019.

25. Liao, C.H.; Yen, H.R. Quantifying the degree of research collaboration: A comparative study of collaborative measures. J. Informetr. 2012, 6, 27-33. [CrossRef]

26. Yu, H.; Wei, Y.-M.; Tang, B.-J.; Mi, Z.; Pan, S.-Y. Assessment on the research trend of low-carbon energy technology investment: A bibliometric analysis. Appl. Energy 2016, 184, 960-970. [CrossRef]

27. Duan, L. Analysis of the relationship between international cooperation and scientific publications in energy R\&D in China. Appl. Energy 2011, 88, 4229-4238.

28. Zhao, W.; Han-shi, Q.; Li-shan, L.; Peng, W.; Dai-qing, Z. Emission Trading Research Trend Analysis Based on Bibliometric. J. Circuits Syst. 2016, 4, 417-424. (In Chinese)

29. Callon, M.; Courtial, J.P.; Laville, F. Co-word analysis as a tool for describing the network of interactions between basic and technological research: The case of polymer chemsitry. Scientometrics 1991, 22, 155-205. [CrossRef]

30. Chen, C. The Centrality of Pivotal Points in the Evolution of Scientific Networks. Intelligence 2005, 98-105. [CrossRef]

31. Braam, R.R.; Moed, H.F.; Raan, A.F.J.V. Mapping of science by combined co-citation and word analysis: II: Dynamical aspects. J. Am. Soc. Inf. Sci. 1991, 42, 252-266. [CrossRef]

32. Garfield, E.; Pudovkin, A.; Istomin, V.S. Algorithmic Citation-Linked Historiography-Mapping the Literature of Science. Proc. Am. Soc. Inf. Sci. Technol. 2005, 39, 14-24. [CrossRef]

33. De Solla Price, D.J. Little Science, Big Science; Columbia University Press: New York, NY, USA, 1963. 
34. Yiming, W.; Zhifu, M.; Hao, Z. Review on climate policy modeling: An analysis based on bibliometrics method. Adv. Earth Sci. 2013, 28, 930-938. (In Chinese)

35. Malik, V.S.; Popkin, B.M.; Bray, G.A.; Després, J.P.; Willett, W.C.; Hu, F.B. Sugar-sweetened beverages and risk of metabolic syndrome and type 2 diabetes: A meta-analysis. Diabetes Care 2010, 33, 2477-2483. [CrossRef]

36. Pakula, C.; Stamminger, R. Electricity and water consumption for laundry washing by washing machine worldwide. Energy Effic. 2010, 3, 365-382. [CrossRef]

37. Monteiro, C.A.; Levy, R.B.; Claro, R.M.; de Castro, I.R.R.; Cannon, G. Increasing consumption of ultra-processed foods and likely impact on human health: Evidence from Brazil. Public Health Nutr. 2011, 14, 5-13. [CrossRef]

38. Moubarac, J.C.; Martins, A.P.B.; Claro, R.M.; Levy, R.B.; Cannon, G.; Monteiro, C.A. Consumption of ultra-processed foods and likely impact on human health. Evidence from Canada. Public Health Nutr. 2013, 16, 2240-2248. [CrossRef] [PubMed]

39. Hubacek, K.; Feng, K.; Chen, B. Changing Lifestyles Towards a Low Carbon Economy: An IPAT Analysis for China. Energies 2011, 5, 22-31. [CrossRef]

40. Xiaohua, W.; Kunquan, L.; Hua, L.; Di, B.; Jingru, L. Research on China's rural household energy consumption-Household investigation of typical counties in 8 economic zones. Renew. Sustain. Energy Rev. 2017, 68, 28-32. [CrossRef]

41. Saidur, R.; Masjuki, H.H.; Jamaluddin, M.Y.; Ahmed, S. Energy and associated greenhouse gas emissions from household appliances in Malaysia. Energy Policy 2007, 35, 1648-1657. [CrossRef]

42. Treloar, G.; Fay, R.; Love, P.E.D.; Iyerraniga, U. Analysing the life-cycle energy of an Australian residential building and its householders. Build. Res. Inf. 2000, 28, 184-195. [CrossRef]

43. Vringer, K.; Blok, K. Long-term trends in direct and indirect household energy intensities: A factor in dematerialisation? Energy Policy 2000, 28, 713-727. [CrossRef]

44. Kayser, H.A. Gasoline demand and car choice: Estimating gasoline demand using household information. Energy Econ. 2000, 22, 331-348. [CrossRef]

45. Mahlia, T.M.I.; Masjuki, H.H.; Saidur, R.; Amalina, M.A. Cost-benefit analysis of implementing minimum energy efficiency standards for household refrigerator-freezers in Malaysia. Energy Policy 2004, 32, 1819-1824. [CrossRef]

46. Kramer, K.J. Greenhouse gas emissions related to Dutch food consumption. Energy Policy 1999, 27, $203-216$. [CrossRef]

47. Du, S.; Lu, B.; Zhai, F.; Popkin, B.M. A new stage of the nutrition transition in China. Public Health Nutr. 2002, 5, 169-174. [CrossRef] [PubMed]

48. Drewnowski, A. Obesity and the food environment: Dietary energy density and diet costs. Am. J. Prev. Med. 2004, 27 (Suppl. 3), 154-162. [CrossRef] [PubMed]

49. Bowman, S.A.; Gortmaker, S.L.; Ebbeling, C.B.; Pereira, M.A.; Ludwig, D.S. Effects of fast-food consumption on energy intake and diet quality among children in a national household survey. Pediatrics 2004, 113 Pt 1, 112-118. [CrossRef] [PubMed]

50. Hann, C.; Rock, C.; King, I.; Drewnowski, A. Validation of the Healthy Eating Index with use of plasma biomarkers in a clinical sample of women. Am. J. Clin. Nutr. 2001, 74, 479. [CrossRef] [PubMed]

51. Florencio, T.T.; Ferreira, H.S.; Cavalcante, J.C.; Luciano, S.M.; Sawaya, A.L. Food consumed does not account for the higher prevalence of obesity among stunted adults in a very-low-income population in the Northeast of Brazil (Maceio, Alagoas). Eur. J. Clin. Nutr. 2003, 57, 1437-1446. [CrossRef] [PubMed]

52. Dendukuri, G.; Mittal, J.P. Household energy needs of a village in the Rayalaseema area of In addition, hra Pradesh, India. Energy Convers. Manag. 1993, 34, 1273-1286. [CrossRef]

53. Sanchez, M.C.; Koomey, J.G.; Moezzi, M.M.; Meier, A.; Huber, W. Miscellaneous electricity in US homes: Historical decomposition and future trends. Energy Policy 1998, 26, 585-593. [CrossRef]

54. Hertwich, E.G. Life cycle approaches to sustainable consumption: A critical review. Environ. Sci. Technol. 2005, 39, 4673-4684. [CrossRef]

55. Gatersleben, B. Sustainable household consumption and quality of life: The acceptability of sustainable consumption patterns and consumer policy strategies. Int. J. Environ. Pollut. 2001, 15, 200-216. [CrossRef]

56. Indra Mahlia, T.M.; Masjuki, H.H.; Choudhury, I.; Saidur, R. Potential $\mathrm{CO}_{2}$ reduction by implementing energy efficiency standard for room air conditioner in Malaysia. Energy Convers. Manag. 2001, 42, 1673-1685. [CrossRef] 
57. Mahlia, T.M.I.; Masjuki, H.H.; Saidur, R.; Amalina, M.A. Viewpoint: Mitigation of emissions through energy efficiency standards for room air conditioners in Malaysia. Energy Policy 2004, 32, 1783-1787. [CrossRef]

58. Judson, R.A.; Schmalensee, R.; Stoker, T.M. Economic Development and the Structure of the Demand for Commercial Energy. Energy 1999, 20, 29-57. [CrossRef]

59. Wang, X.; Feng, Z.; Gao, X.; Jiang, K. On household energy consumption for rural development: A study on Yangzhong county of China. Energy 1999, 24, 493-500. [CrossRef]

60. Mills, B.; Schleich, J. What's driving energy efficient appliance label awareness and purchase propensity? Energy Policy 2010, 38, 814-825. [CrossRef]

61. Athukorala, P.P.A.W.; Wilson, C. Estimating short and long-term residential demand for electricity: New evidence from Sri Lanka. Energy Econ. 2010, 32, S34-S40. [CrossRef]

62. Deutsch, M. Life Cycle Cost Disclosure, Consumer Behavior, and Business Implications. J. Ind. Ecol. 2010, 14, 103-120. [CrossRef]

63. Ueno, T.; Sano, F.; Saeki, O.; Tsuji, K. Effectiveness of an energy-consumption information system on energy savings in residential houses based on monitored data. Appl. Energy 2006, 83, 166-183. [CrossRef]

64. Ouyang, J.; Hokao, K. Energy-saving potential by improving occupants' behavior in urban residential sector in Hangzhou City, China. Energy Build. 2009, 41, 711-720. [CrossRef]

65. Shan, H.; Da, Y.; Guo, S.; Ying, C.; Bing, D. A survey on energy consumption and energy usage behavior of households and residential building in urban China. Energy Build. 2017, 148, 366-378.

66. Brounen, D.; Kok, N.; Quigley, J.M. Residential energy use and conservation: Economics and demographics. Eur. Econ. Rev. 2012, 56, 931-945. [CrossRef]

67. Tiefenbeck, V.; Staake, T.; Roth, K.; Sachs, O. For better or for worse? Empirical evidence of moral licensing in a behavioral energy conservation campaign. Energy Policy 2013, 57, 160-171. [CrossRef]

68. Martin-Biggers, J.; Spaccarotella, K.; Berhaupt-Glickstein, A.; Hongu, N.; Worobey, J.; Byrd-Bredbenner, C. Come and get it! A discussion of family mealtime literature and factors affecting obesity risk. Adv. Nutr. 2014, 5, 235. [CrossRef] [PubMed]

69. Malik, V.S.; Willett, W.C.; Hu, F.B. Global obesity: Trends, risk factors and policy implications. Nat. Rev. Endocrinol. 2013, 9, 13-27. [CrossRef] [PubMed]

70. Bouzarovski, S.; Petrova, S. A global perspective on domestic energy deprivation: Overcoming the energy poverty-fuel poverty binary. Energy Res. Soc. Sci. 2015, 10, 31-40. [CrossRef]

71. Edwards, P.; Roberts, I. Population adiposity and climate change. Int. J. Epidemiol. 2009, 38, 1137-1140. [CrossRef]

72. Higgins, P.A.T. Exercise-based transportation reduces oil dependence, carbon emissions and obesity. Environ. Conserv. 2005, 32, 197-202. [CrossRef]

73. Herendeen, R.; Tanaka, J. Energy cost of living. Energy 1976, 1, 165-178. [CrossRef]

74. Kok, R.; Benders, R.M.J.; Moll, H.C. Measuring the environmental load of household consumption using some methods based on input-output energy analysis: A comparison of methods and a discussion of results. Energy Policy 2006, 34, 2744-2761. [CrossRef]

75. Druckman, A.; Jackson, T. The carbon footprint of UK households 1990-2004: A socio-economically disaggregated, quasi-multi-regional input-output model. Ecol. Econ. 2009, 68, 2066-2077. [CrossRef]

76. Willis, L.D. Tax Policy: Effects of the Alcohol Fuels Tax Incentives; U.S. Government Accountability Office: Washington, DC, USA, 1997.

77. Zha, D.; Dequn, Z.; Peng, Z. Driving forces of residential $\mathrm{CO}_{2}$ emissions in urban and rural China: An index decomposition analysis. Energy Policy 2010, 38, 3377-3383.

78. Duarte, R.; Mainar, A.; Sánchez-Chóliz, J. The impact of household consumption patterns on emissions in Spain. Energy Econ. 2010, 32, 176-185. [CrossRef]

79. Ekholm, T.; Krey, V.; Pachauri, S.; Riahi, K. Determinants of household energy consumption in India. Energy Policy 2010, 38, 5696-5707. [CrossRef]

80. Berkhout, P.H.G.; Muskens, J.C.; Velthuijsen, J.W. Defining the rebound effect. Energy Policy 2000, 28, 425-432. [CrossRef]

81. Hertwich, E. Consumption and the rebound effect. J. Ind. Ecol. 2005, 9, 85-98. [CrossRef]

82. Chitnis, M.; Sorrell, S. Living up to expectations: Estimating direct and indirect rebound effects for UK households. Energy Econ. 2015, 52, S100-S116. [CrossRef] 
83. Fischer, C. Feedback on household electricity consumption: A tool for saving energy? Energy Effic. 2008, 1, 79-104. [CrossRef]

84. Carrico, A.R.; Riemer, M. Motivating energy conservation in the workplace: An evaluation of the use of group-level feedback and peer education. J. Environ. Psychol. 2011, 31, 1-13. [CrossRef]

85. Asensio, O.I.; Delmas, M.A. Nonprice incentives and energy conservation. Proc. Natl. Acad. Sci. USA 2015, 112, 510-515. [CrossRef]

(C) 2019 by the authors. Licensee MDPI, Basel, Switzerland. This article is an open access article distributed under the terms and conditions of the Creative Commons Attribution (CC BY) license (http://creativecommons.org/licenses/by/4.0/). 